\title{
Impact of microgrid operation on performance of radial distribution system
}

\author{
SHALAKA CHAPHEKAR* ${ }^{*}$ and ANJALI DHARME \\ Department of Electrical Engineering, College of Engineering, Pune, India \\ e-mail: shalakachaphekar@yahoo.co.in; dharme@ rediffmail.com
}

MS received 23 May 2018; revised 22 August 2019; accepted 28 August 2019

\begin{abstract}
Voltage profile and real power loss are the criteria in determining performance of Radial Distribution System (RDS). Presence of Distributed Generators in RDS is assessed by 'Penetration Ratio'. The use of PR fails in the analysis of the implications of the presence of a Microgrid on RDS as it is zero in islanded mode and sometimes in grid-connected mode. An attempt has been made to introduce a new term 'Relief Factor' to overcome this lacuna. This Factor is evaluated by developing an algorithm based on power flow analysis using Backward Forward Sweep method. The developed algorithm is tested on a 34 bus RDS by integration of a twoshift industrial Microgrid. The power flow analysis is run for 24 snapshots of the day. Relief Factor is found to be suitable to analyze the impact of a Microgrid on the performance of RDS in both the modes of Microgrid operation viz. grid-connected mode and islanded mode.
\end{abstract}

Keywords. Radial distribution system; microgrid; power flow; penetration ratio.

\section{Introduction}

Microgrid is defined as a single controllable system, which consists of a cluster of loads and distributed sources that provides power to its nearby area. The coordinated operation of Microgrid components fulfills local energy needs for reliability and security [1]. Microgrid operates in two modes - Grid Connected Mode and Islanded Mode [2]. As a new paradigm in power system, deployment of Microgrids brings several benefits to the utilities and consumers viz. enhanced reliability, reduced emissions, use of local resources, low transmission and distribution (T\&D) losses, higher energy efficiency [3, 4]. Despite these advantages, Microgrid research deals with a variety of issues like selection, scheduling and sizing of power generation as well as storage devices, support for improving grid performance, application of power electronic instruments, economics, protection, communication and control [5]. Extensive literature survey on Microgrid operation explains the importance of energy and power management of Microgrid to enhance its performance. Most literature on energy management of Microgrid deals with optimization of Microgrid components [6-8]. Studies on power management explain controlling aspect of a Microgrid [9-11].

It is the voltage profile and real power loss that determine performance of RDS. These criteria are analyzed using different power flow methods. Backward Forward Sweep

*For correspondence

Published online: 03 October 2019
(BFS) method is the most common one used to evaluate these criteria for RDS [12].

There is plenty of literature available on impact of DGs on distribution systems [13, 14]. Power available from a DG indicates the penetration of power in RDS. This available power for RDS is defined as 'Penetration Ratio' (PR) [15]. In case of integration of a Microgrid in RDS, the power exported by a Microgrid is evaluated as PR. The value of PR becomes zero in islanded mode as well as sometimes in grid connected mode of a Microgrid. So, use of PR fails to assess performance of RDS in the presence of a Microgrid.

Some studies are focused on steady state performance of the distribution systems with Microgrids. According to author's knowledge, these studies do not assess the performance of RDS in terms of PR. Distribution management system of a Microgrid plays an important role in minimizing negative impact of the DG penetration [16-18]. Microgrid works as a source or as a load depending on its demand supply balance when it gets connected to RDS at the point of common coupling (PCC). But implications of the presence of a Microgrid on performance of RDS are left untouched. In this context, an attempt has been made to establish correlation between Microgrid generation and total demand of a distribution system. This relationship is addressed as the Relief Factor (RF). This factor is evaluated for grid connected mode as well as the islanded mode of Microgrid operation.

The proposed work is presented in two stages. The first stage analyses the influence of a Microgrid on the voltage 
profile and real power loss in the standard system using BFS method of power flow. The implications of the presence of a Microgrid on the RDS are assessed in terms of penetration ratio and Relief Factor. In the second stage, availability based power management of the Microgrid generation is implemented for the RDS performance assessment.

The rest of the paper is organized as follows. Section 2 describes determination of voltage profile and system losses of the RDS due to integration of a Microgrid. Section 3 explains the impact of a Microgrid on the RDS due to PR and RF. System configuration of the RDS and the real case study of a two-shift industrial Microgrid is presented in section 4. Section 5 gives numerical results with discussion, investigating implications of the presence of the Microgrid on the RDS performance. Section 6 outlines the conclusion.

\section{Determination of voltage variation and system losses in RDS with microgrids}

Introduction of generating sources in distribution networks brings significant influence on voltage conditions of consumers and utility equipment [19, 20]. The controlled output by distributed generation (DG) units providing power to their adjacent loads has brought the appearance of the Microgrid. Electric utility deregulation and restructuring have encouraged Microgrids penetration into distribution networks. Successful penetration of Microgrids in distribution systems must be technically feasible and economically viable for both Microgrid owners and utility. In order to achieve full benefit from Microgrid, one of the primary requirements is the accurate power flow analysis of RDS in the presence of a Microgrid. Integration of a Microgrid in RDS can beachieved by designing the appropriate power management strategy for different generators units in a Microgrid [9]. Impact of a Microgrid on RDS is dependent on coordination between the availability of renewable generation, storage device and demand of a Microgrid. This introduces variation in the exported power from a Microgrid to an $\mathrm{RDS}$.

The total active power loss in an RDS is derived from power flow analysis and is given as follows:

$$
\mathrm{P}_{\text {loss }}=\sum_{\mathrm{i}=1}^{\mathrm{m}}\left(\mathrm{I}_{\mathrm{i}}\right)^{2} \mathrm{R}_{\mathrm{i}}
$$

A mismatch between supply and demand will deteriorate the stability and quality of the power supply in terms of voltage and security of a distribution system. To maintain the power balance in a distribution system, demand and power losses should be equal to the power supplied from Maingrid. Thus, power balance equations are formulated as (2) and (3).

$$
\begin{gathered}
\mathrm{P}_{\mathrm{G}}=\mathrm{P}_{\mathrm{D}}+\mathrm{P}_{\text {loss }} \\
\mathrm{Q}_{\mathrm{G}}=\mathrm{Q}_{\mathrm{D}}+\mathrm{Q}_{\text {loss }}
\end{gathered}
$$

Equations (2) and (3) are rewritten as demand-supply balance constraints for an RDS as (4) and (5)

$$
\begin{aligned}
& \sum_{\mathrm{t}=1}^{\mathrm{T}} \mathrm{P}_{\mathrm{G}_{\text {MAINGRID }}}(\mathrm{t}) \mathrm{d} \mathrm{t} \pm \sum_{\mathrm{t}=1}^{\mathrm{T}} \mathrm{P}_{\mu \mathrm{G}}^{\mathrm{in}}(\mathrm{t}) \mathrm{d} \mathrm{t} \\
& =\sum_{\mathrm{t}=1}^{\mathrm{T}} \mathrm{P}_{\text {DMAINGRID }}(\mathrm{t}) \mathrm{dt}+\sum_{\mathrm{t}=1}^{\mathrm{T}} \mathrm{P}_{\text {loss }}(\mathrm{t}) \mathrm{dt} \\
& \sum_{\mathrm{t}=1}^{\mathrm{T}} \mathrm{Q}_{\mathrm{G}_{\text {MAINGRID }}}(\mathrm{t}) \mathrm{d} \mathrm{t} \pm \sum_{\mathrm{t}=1}^{\mathrm{T}} \mathrm{Q}_{\mu \mathrm{G}}^{\mathrm{in}}(\mathrm{t}) \mathrm{dt} \\
& =\sum_{\mathrm{t}=1}^{\mathrm{T}} \mathrm{Q}_{\text {D MAINGRID }}(\mathrm{t}) \mathrm{dt}+\sum_{\mathrm{t}=1}^{\mathrm{T}} \mathrm{Q}_{\text {loss }}(\mathrm{t}) \mathrm{dt}
\end{aligned}
$$

The limits of the active power of DGs and standard limits of the voltage at each bus are given in Eqs. (6) and (7).

$$
\begin{gathered}
\mathrm{P}_{\mathrm{DG}_{\min }} \leq \mathrm{P}_{\mathrm{DG}_{\mathrm{i}}} \leq P_{\mathrm{DG}_{\max }} \quad \mathrm{i}=1,2, \ldots \mathrm{N} \\
\mathrm{V}_{\mathrm{i}}^{\min } \leq \mathrm{V}_{\mathrm{i}} \leq \mathrm{V}_{\mathrm{i}}^{\max }
\end{gathered}
$$

$\mathrm{P}_{\mu \mathrm{G}}^{\mathrm{in}}$ is calculated as

$$
P_{\mu G}^{\text {in }}=P_{G \mu G}-P_{D \mu G}
$$

$\mathrm{P}_{\mu \mathrm{G}}^{\mathrm{in}}$ is the total power exported by a Microgrid in RDS at Point of Common Coupling (PCC). At PCC, bidirectional power flow takes place between a Microgrid and an RDS depending on the demand- supply balance in a Microgrid.

\section{Performance assessment of RDS using penetration ratio and relief factor}

Power exchanged between a Microgrid and an $\operatorname{RDS}\left(\mathrm{P}_{\mu \mathrm{G}}^{\mathrm{in}}\right)$ decides nature of a Microgrid (as a source or as a load) from perspective of an RDS. Presence of storage devices in a Microgrid introduces flexibility in Microgrid operation. Proper coordination between use of available renewable generation and storage device controls the demand -supply gap in a Microgrid making it more advantageous over a distributed generator. A Microgrid can absorb the excess power in the grid during off-peak hours of Maingrid. Penetration of power by a Microgrid in a distribution system is assessed as PR. PR decides the power fed by a Microgrid in RDS.

Penetration Ratio (P.R.) of a Microgrid is denoted by $\lambda$ and given as [15], 


$$
\lambda=\frac{\mathrm{P}_{\mu G}^{\text {in }}}{\mathrm{P}_{\mathrm{D}}}
$$

PR is significant in grid connected mode of Microgrid operation. But in islanded mode, PR is zero. Implications of the presence of a Microgrid on RDS are left untouched while discussing the concept of PR. Effect of the presence of a Microgrid (under its various modes of operation) on RDS performance is assessed in this work by defining the new term 'Relief Factor $(\sigma)$ '. 'Relief Factor' proves to be more appropriate than 'Penetration Ratio' while analysing implications of the presence of a Microgrid on RDS performance.

Microgrid is operated in two modes: grid connected mode and islanded mode. Accordingly, Relief Factor (R.F.) is defined for two operational modes.

a. Islanded mode:

$$
\sigma=\frac{\mathrm{P}_{\mathrm{D} \mu \mathrm{G}}}{\mathrm{P}_{\mathrm{D}}}=\frac{\mathrm{P}_{\mathrm{G} \mu \mathrm{G}}}{\mathrm{P}_{\mathrm{D}}}
$$

b. Grid connected mode:

i. Microgrid as a source

$$
\sigma=\frac{\mathrm{P}_{\mu \mathrm{G}}^{\mathrm{in}}+\mathrm{P}_{\mathrm{D} \mu \mathrm{G}}}{\mathrm{P}_{\mathrm{D}}}=\frac{P_{\mathrm{G} \mu \mathrm{G}}}{\mathrm{P}_{\mathrm{D}}}
$$

ii. Microgrid as a load

$$
\boldsymbol{\sigma}=\frac{P_{\mathrm{D} \mu \mathrm{G}}-\mathrm{P}_{\mu \mathrm{G}}^{\mathrm{in}}}{\mathrm{PD}}=\frac{\mathrm{P}_{\mathrm{G} \mu \mathrm{G}}}{\mathrm{PD}}
$$

The effect of the presence of a Microgrid in RDS is analyzed by evaluating penetration ratio and Relief Factor. The flowchart for the analysis is presented in figure 1 .

\section{System configuration}

Excessive burden of demands and/or long lengths of an RDS severely affects the farthest end of an RDS. Voltage profile as well as system losses of an RDS are evaluated by integration of a Microgrid. To investigate the implications of a Microgrid on the RDS, 34 bus, 5.4 MVA, $11 \mathrm{kV}$ standard system is considered as a case study and is shown in figure 2.

The real case study of a Microgrid with a two-shift industrial consumer is described to analyze its impact on the RDS. This study may imitate deployment of several Microgrids to analyze their impact on the performance of the RDS. Hourly data of a two-shift industrial consumer is

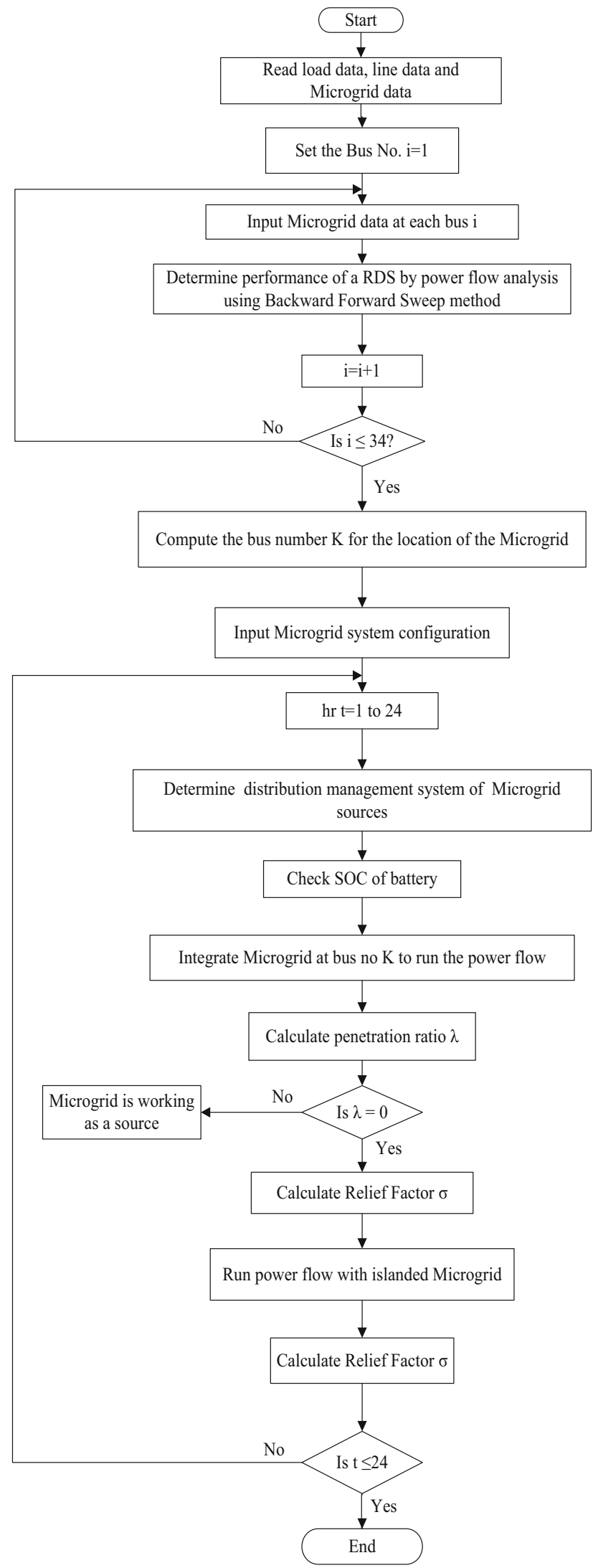

Figure 1. Flowchart for the evaluation of penetration ratio and relief factor. 


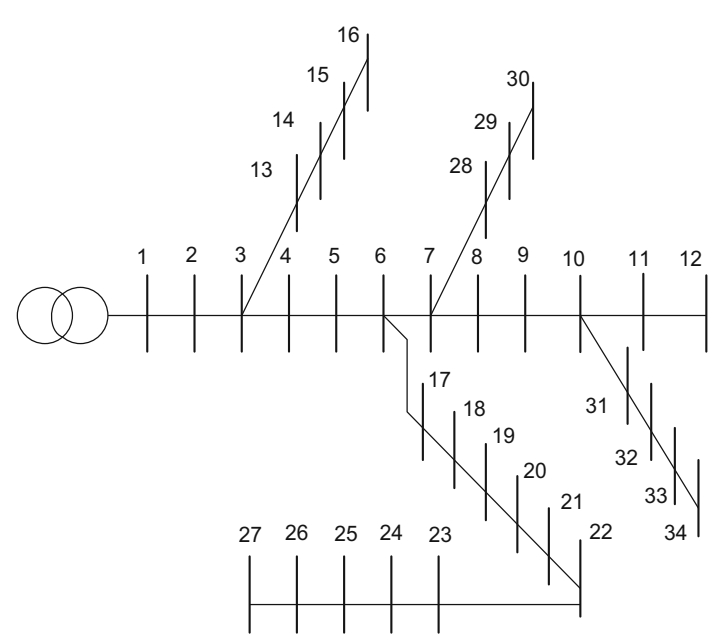

Figure 2. Single Line Diagram of 34 Bus Test System [21].

collected for a month's duration and is averaged out to plot the load curves. Wind speed and solar irradiance data at Virewa $\left(22.03^{\circ} \mathrm{N}, 71.46^{\circ} \mathrm{E}\right)$ (Gujarat, India) is scaled for the Microgrid sources in this paper.

Table 1 shows the Microgrid configuration.

Power management strategy of a Microgrid is one of the main criteria to decide its impact on RDS. It is assumed that the Microgrid under consideration has four energy sources viz. solar PV, wind, battery and diesel generator. Depending on the availability of renewable resources, distributed generators would generate power. It is assumed that there is no load shedding in the Microgrid. Reliability of power is ensured by the use of the diesel generator. Power management strategy of the Microgrid is decided depending on its mode of operation [22-25].

Case (i): Grid connected mode

- Energy generated by the renewables has the highest priority to supply the demand.

- Power is exported to the utility in case of excess generation from renewables after fulfilling demand and charging of battery.

- Power is imported by the Microgrid in case of deficit of supply of power by renewables.

\section{Case (ii): Islanded mode}

- Excess power from renewables is used for battery charging.

Table 1. Microgrid system configuration.

\begin{tabular}{ll}
\hline Maximum Load & $1500 \mathrm{~kW}$ \\
Solar PV System & $450 \mathrm{~kW}$ \\
Wind Generator & $750 \mathrm{~kW}$ \\
Battery Capacity & $1000 \mathrm{Ah}, 24 \mathrm{~V}(30 \mathrm{No})$. \\
Diesel Generator & $1800 \mathrm{kVA}, 415 \mathrm{~V}, 3 \mathrm{ph}, 50 \mathrm{~Hz}$, \\
& $0.8 \mathrm{p.} \mathrm{f.}$ \\
\hline
\end{tabular}

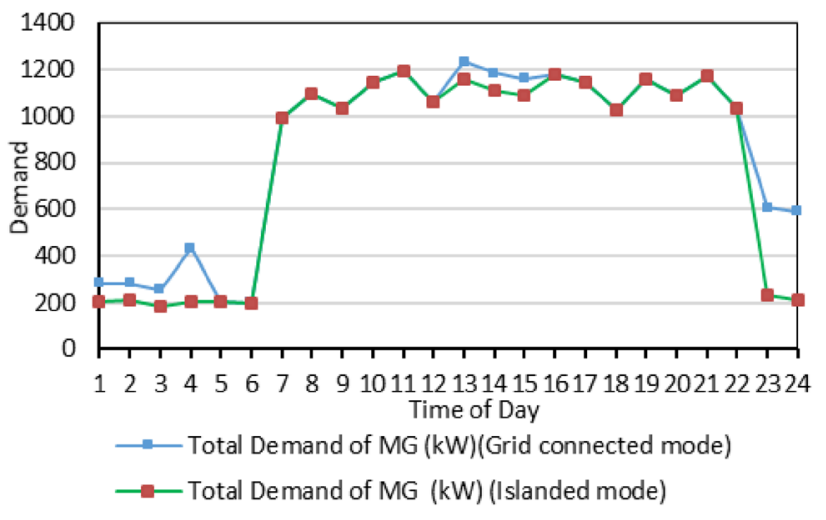

Figure 3. Daily load curves of the two shift industrial consumer.

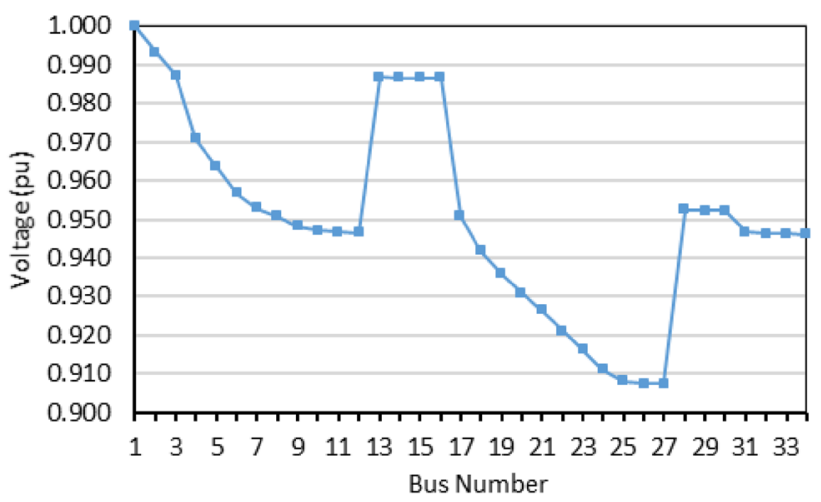

Figure 4. Voltage profile of 34 bus system without Microgrid.

- If PV and wind generation are not enough to meet the power required by the load, storage will be turned on to satisfy the demand.

- Diesel generator is switched on to supply the load only if the demand is greater than generation by renewable sources.

Figure 3 shows the load curves of the two-shift industrial consumer of the Microgrid for islanded and grid connected mode.

\section{Results and discussion}

Voltage profile of 34 bus RDS is determined by power flow analysis using BFS method and is shown in figure 4.

Laterals are connected at bus Nos. 3, 6, 7 and 10. Therefore, a different voltage profile appears when the graph is plotted as per the sequence of bus numbers. It is observed that the voltage is much reduced for the lateral which originated from bus No. 6 (bus No. 17 to 27). The voltage at Bus No. 27 (0.9273 p. u.) is found to be the lowest than any other bus and even lower than the voltage at Bus No. 12 (0.9505 p. u.). 

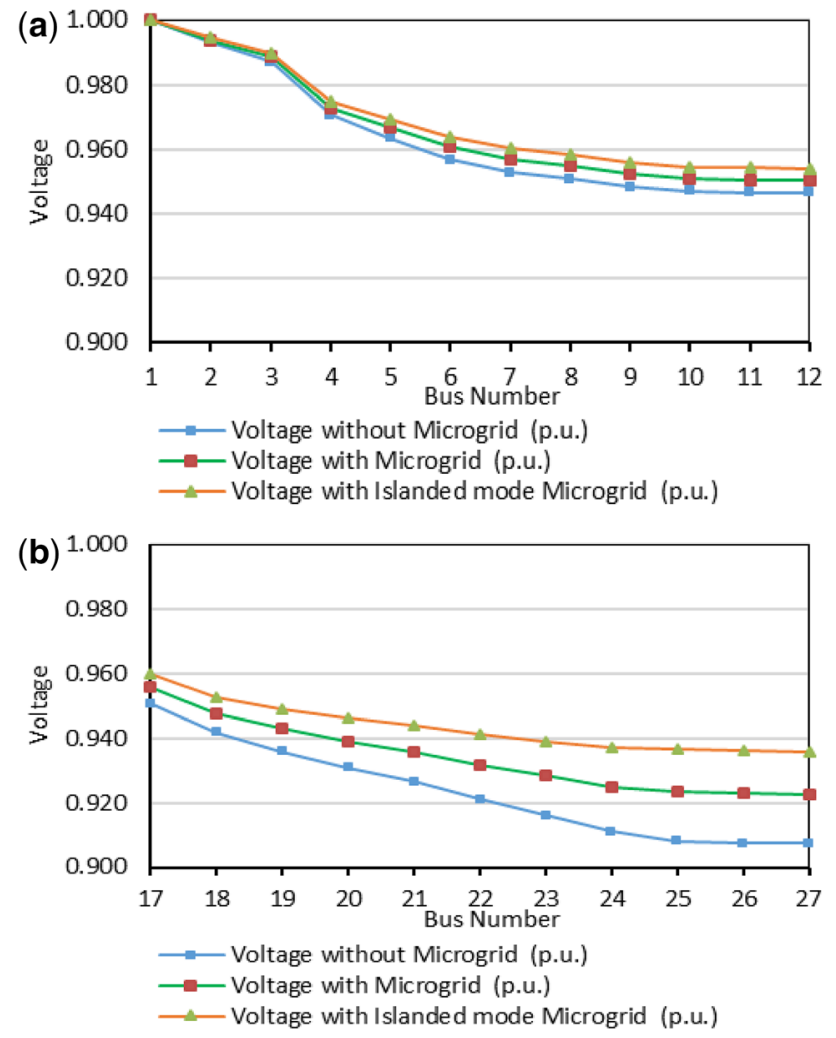

Figure 5. (a) Voltage Profile of RDS (1-12) with and without Microgrid. (b). Voltage Profile of lateral (17-27) with and without Microgrid.
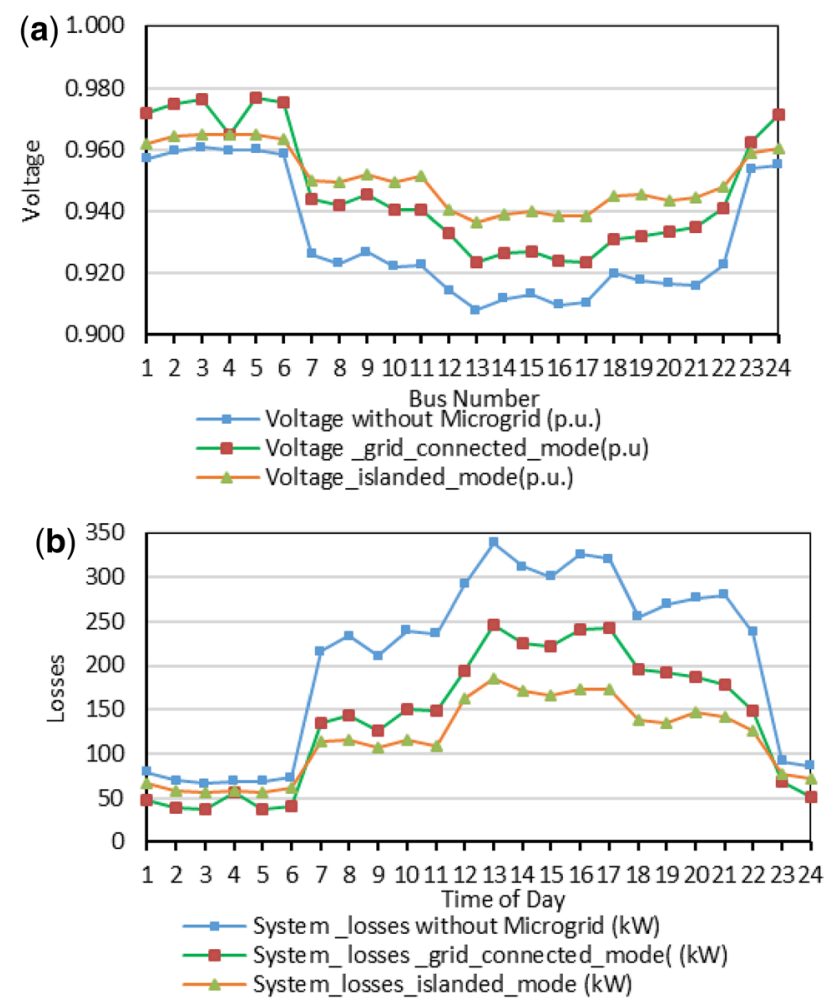

Figure 6. (a) Voltage at Bus No. 25 with and without Microgrid. (b) RDS loss with Microgrid at Bus No. 25.

\subsection{Determination of voltage variation and system losses in the RDS with microgrids}

Voltage profile and system losses are the two criteria to decide the location of a Microgrid connected to an RDS. Optimum placement of the Microgrid in the RDS is obtained with the objective of system loss minimization by developing the code in MATLAB. The optimum location is found to be at Bus No. 25. The results of the voltages of the RDS (1-12) and (17-27) are shown in the figure 5(a) and (b) in the presence of the Microgrid.

It is observed from figures 4,5(a) and (b) that the voltage profile of the RDS is improved in the presence of the Microgrid. Voltage profile of the RDS is urther upgraded after islanding of Microgrid from the main system. Thus, it is observed that voltage profile of the RDS is independent of modes of Microgrid operation.

System load variation as per the actual load curve is considered for 24 slots of the day in power flow analysis. Load for $1 \mathrm{~h}$ is assumed to be constant. 24 such snapshots are analyzed through power flow to investigate the voltages and system losses for different load conditions. Figure 6(a) presents variation in the voltage level at bus No. 25 for $24 \mathrm{~h}$ of the day. Figure 6(b) shows the RDS loss for $24 \mathrm{~h}$ load variation with and without Microgrid.

Figure 6(a) indicates that the voltage at bus No. 25 is analyzed for 24 snapshots $(24 \mathrm{~h})$ and gets improved in islanded mode $(3.1 \%)$ than in grid connected mode $(1.6 \%)$ at peak demand of the RDS. Figure 6(b) shows that there is substantial reduction in the system losses when the Microgrid is connected to the RDS (27\%) at bus no.25. It further indicates reduction of the system losses is even more in islanded mode of Microgrid (45\%) than grid connected mode $(27 \%)$.

\subsection{Performance assessment of the RDS using penetration ratio and relief factor}

Though optimal placement of the Microgrid improves voltage profile of the RDS and reduces system losses, it is obligatory to check the impact of the Microgrid on the RDS in terms of PR and Relief Factor. The implications of the presence of two shift industrial Microgrid are investigated by evaluating PR and Relief Factor along with the voltage profile and system losses of the RDS for three cases. They are:

Case I RDS without Microgrid

Case II RDS with Microgrid

Case III RDS with islanded Microgrid

Table 2 presents the performance of the RDS without integration of the Microgrid.

It is observed from table 2 that,

- Voltage profile of the RDS is deteriorated as the demand of the Microgrid is supplied by the distribution system. 
Table 2. Case I: RDS without Microgrid.

\begin{tabular}{|c|c|c|c|c|}
\hline Time of day & RDS demand (kW) & Microgrid demand on bus no. $25(\mathrm{~kW})$ & Voltage profile at bus no. 25 (p. u) & System losses $(\mathrm{kW})$ \\
\hline $0-1$ & 2845.01 & 207.97 & 0.9571 & 79.13 \\
\hline $1-2$ & 2674.50 & 209.25 & 0.9596 & 69.92 \\
\hline $2-3$ & 2622.24 & 180.56 & 0.9607 & 66.52 \\
\hline $3-4$ & 2668.17 & 207.82 & 0.9598 & 69.11 \\
\hline $4-5$ & 2649.86 & 204.81 & 0.9600 & 68.58 \\
\hline $5-6$ & 2752.53 & 200.72 & 0.9586 & 73.74 \\
\hline $6-7$ & 4422.64 & 991.83 & 0.9262 & 216.49 \\
\hline $7-8$ & 4553.64 & 1097.50 & 0.9232 & 233.21 \\
\hline $8-9$ & 4356.99 & 1034.25 & 0.9270 & 211.18 \\
\hline $9-10$ & 4597.03 & 1144.07 & 0.9221 & 239.87 \\
\hline $10-11$ & 4543.37 & 1193.91 & 0.9226 & 236.50 \\
\hline $11-12$ & 5114.58 & 1058.90 & 0.9146 & 292.30 \\
\hline $12-13$ & 5472.78 & 1159.07 & 0.9080 & 338.77 \\
\hline $13-14$ & 5266.06 & 1110.08 & 0.9117 & 311.99 \\
\hline $14-15$ & 5179.33 & 1086.41 & 0.9133 & 301.13 \\
\hline $15-16$ & 5349.90 & 1179.56 & 0.9096 & 325.99 \\
\hline $16-17$ & 5319.40 & 1145.52 & 0.9105 & 320.43 \\
\hline $17-18$ & 4792.29 & 1029.46 & 0.9200 & 255.08 \\
\hline $18-19$ & 4877.68 & 1155.94 & 0.9176 & 269.30 \\
\hline $19-20$ & 4956.87 & 1092.11 & 0.9168 & 276.16 \\
\hline $20-21$ & 4972.61 & 1170.05 & 0.9160 & 280.18 \\
\hline $21-22$ & 4621.32 & 1036.31 & 0.9227 & 237.62 \\
\hline $22-23$ & 3058.30 & 230.79 & 0.9537 & 92.05 \\
\hline $23-24$ & 2971.52 & 213.62 & 0.9552 & 86.50 \\
\hline
\end{tabular}

Table 3. Case II: RDS with Microgrid: Grid connected mode- Microgrid as a load/source.

\begin{tabular}{|c|c|c|c|c|c|c|c|c|c|c|}
\hline $\begin{array}{l}\text { Time } \\
\text { of } \\
\text { day }\end{array}$ & $\begin{array}{c}\text { RDS } \\
\text { demand } \\
(\mathrm{kW})\end{array}$ & $\begin{array}{c}\text { MG } \\
\text { demand on } \\
\text { bus no. } 25 \\
(\mathrm{~kW})\end{array}$ & $\begin{array}{c}\text { Total } \\
\text { demand on } \\
\text { bus no. } 25 \\
(\mathrm{~kW})\end{array}$ & $\begin{array}{c}\text { Total } \\
\text { generation } \\
\text { of microgrid } \\
(\mathrm{kW})\end{array}$ & $\begin{array}{l}\text { Power } \\
\text { taken by } \\
\text { microgrid } \\
(\mathrm{kW})\end{array}$ & $\begin{array}{l}\text { Power } \\
\text { exported by } \\
\text { microgrid } \\
(\mathrm{kW})\end{array}$ & $\begin{array}{l}\text { Voltage profile } \\
\text { at bus no. } 25 \\
\text { with MG (p. u.) }\end{array}$ & $\begin{array}{l}\text { System } \\
\text { losses } \\
\text { with MG } \\
(\mathrm{kW})\end{array}$ & P.R. & R.F. \\
\hline $0-1$ & 2215.01 & 207.97 & 282.97 & 705.00 & 0.00 & 422.03 & 0.9718 & 47.48 & 0.191 & 0.318 \\
\hline $1-2$ & 2007.30 & 209.25 & 284.25 & 742.20 & 0.00 & 457.95 & 0.9750 & 39.59 & 0.228 & 0.370 \\
\hline $2-3$ & 1955.04 & 180.56 & 255.56 & 742.20 & 0.00 & 486.64 & 0.9762 & 37.62 & 0.249 & 0.380 \\
\hline $3-4$ & 2450.97 & 207.82 & 732.82 & 742.20 & 0.00 & 9.38 & 0.9649 & 56.88 & 0.004 & 0.303 \\
\hline $4-5$ & 1926.26 & 204.81 & 204.81 & 723.60 & 0.00 & 518.79 & 0.9768 & 37.14 & 0.269 & 0.376 \\
\hline $5-6$ & 2028.33 & 200.72 & 200.72 & 724.20 & 0.00 & 523.48 & 0.9753 & 40.88 & 0.258 & 0.357 \\
\hline $6-7$ & 3683.14 & 991.83 & 991.83 & 739.50 & 252.33 & 0.00 & 0.9441 & 134.82 & 0.000 & 0.201 \\
\hline $7-8$ & 3773.34 & 1097.50 & 1097.50 & 780.30 & 317.20 & 0.00 & 0.9421 & 142.65 & 0.000 & 0.207 \\
\hline $8-9$ & 3579.69 & 1034.25 & 1034.25 & 777.30 & 256.95 & 0.00 & 0.9457 & 126.74 & 0.000 & 0.217 \\
\hline $9-10$ & 3847.63 & 1144.07 & 1144.07 & 749.40 & 394.67 & 0.00 & 0.9403 & 150.07 & 0.000 & 0.195 \\
\hline $10-11$ & 3811.37 & 1193.91 & 1193.91 & 732.00 & 461.91 & 0.00 & 0.9403 & 148.18 & 0.000 & 0.192 \\
\hline $11-12$ & 4366.68 & 1058.90 & 1058.90 & 747.90 & 311.00 & 0.00 & 0.9329 & 193.50 & 0.000 & 0.171 \\
\hline $12-13$ & 4854.78 & 1159.07 & 1234.07 & 693.00 & 541.07 & 0.00 & 0.9233 & 245.93 & 0.000 & 0.143 \\
\hline $13-14$ & 4666.06 & 1110.08 & 1185.08 & 675.00 & 510.08 & 0.00 & 0.9265 & 226.23 & 0.000 & 0.145 \\
\hline $14-15$ & 4613.23 & 1086.41 & 1161.41 & 641.10 & 520.31 & 0.00 & 0.9272 & 221.49 & 0.000 & 0.139 \\
\hline $15-16$ & 4774.80 & 1179.56 & 1179.56 & 575.10 & 604.46 & 0.00 & 0.9239 & 240.23 & 0.000 & 0.120 \\
\hline $16-17$ & 4797.70 & 1145.52 & 1145.52 & 521.70 & 623.82 & 0.00 & 0.9234 & 242.96 & 0.000 & 0.109 \\
\hline $17-18$ & 4334.49 & 1029.46 & 1029.46 & 457.80 & 571.66 & 0.00 & 0.9312 & 195.46 & 0.000 & 0.106 \\
\hline $18-19$ & 4294.78 & 1155.94 & 1155.94 & 582.90 & 573.04 & 0.00 & 0.9319 & 191.54 & 0.000 & 0.136 \\
\hline 19-20 & 4269.87 & 1092.11 & 1092.11 & 687.00 & 405.11 & 0.00 & 0.9336 & 186.49 & 0.000 & 0.161 \\
\hline $20-21$ & 4192.61 & 1170.05 & 1170.05 & 780.00 & 390.05 & 0.00 & 0.9351 & 178.46 & 0.000 & 0.186 \\
\hline $21-22$ & 3859.92 & 1036.31 & 1036.31 & 761.40 & 274.91 & 0.00 & 0.9412 & 148.88 & 0.000 & 0.197 \\
\hline $22-23$ & 2690.50 & 230.79 & 530.79 & 667.80 & 0.00 & 137.01 & 0.9623 & 68.99 & 0.051 & 0.248 \\
\hline $23-24$ & 2285.12 & 213.62 & 213.62 & 686.40 & 0.00 & 472.78 & 0.9712 & 50.89 & 0.207 & 0.300 \\
\hline
\end{tabular}




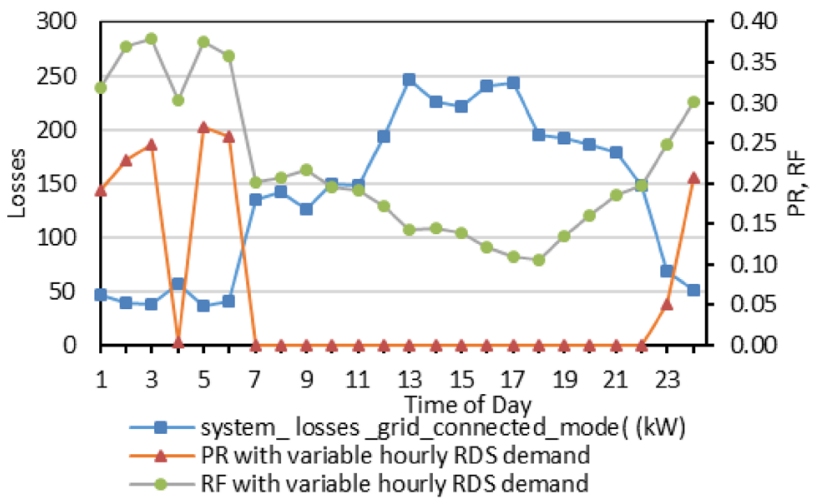

Figure 7. Correlation between system losses and relief factor (grid-connected mode).

The implications of the presence of the Microgrid as a load or as a source on the RDS are tabulated in table 3. PR and Relief Factor are computed for variable demand of the RDS. The variation in the RDS demand is considered after everyone hour. Relief Factor for the RDS is calculated using Eqs. (11) and (12) for both modes of Microgrid operation.

Table 3 shows that,

- The Microgrid is working as a load from 6 a.m. to 10 p.m. for the RDS i.e., PR is zero.
- Though PR is zero during peak demand of the RDS, Microgrid reduces its power import from the RDS. Presence of the Microgrid in the RDS is determined as 'Relief Factor'.

Integration of the Microgrid has brought its representation as a source or as a load to the utility. This modification in the role of the Microgrid is assessed as PR. It is worth noting that PR is depiction of the Microgrid from RDS perspective when it is evaluated for grid connected mode of Microgrid operation. It is zero when the power exported by the Microgrid to the RDS is zero. In such case, the impact of Microgrid on RDS performance is evaluated in terms of Relief Factor.

Figure 7 shows correlation between system losses and Relief Factor for grid connected mode of Microgrid.

Figure 7 shows that RDS performance cannot be assessed in terms of PR. However, the impact of the presence of a Microgrid on RDS performance can be established by Relief Factor. It is observed that the system losses are reduced with increase in Relief Factor and vice versa. This correlation is shown in figure 7.

The influence of a Microgrid on RDS performance can not be determined by PR due to plug and play operation of a Microgrid. Relief Factor given by Eq. (10) is used to assess the performance of the RDS in islanded mode of Microgrid operation. Table 4 shows the performance of the RDS with islanded mode of Microgrid operation.

Table 4. Case III: RDS with Islanded mode of Microgrid (penetration ratio, $\lambda=0$ ).

\begin{tabular}{|c|c|c|c|c|c|c|c|}
\hline $\begin{array}{l}\text { Time } \\
\text { of } \\
\text { day }\end{array}$ & $\begin{array}{c}\text { RDS } \\
\text { demand } \\
(\mathrm{kW})\end{array}$ & $\begin{array}{l}\text { MG demand } \\
\text { without battery } \\
(\mathrm{kW})\end{array}$ & $\begin{array}{l}\text { Total demand of } \\
\text { microgrid with } \\
\text { battery }(\mathrm{kW})\end{array}$ & $\begin{array}{l}\text { Total generation } \\
\text { of microgrid } \\
(\mathrm{kW})\end{array}$ & $\begin{array}{l}\text { Voltage profile of bus no. } \\
25 \text { with islanded MG (p. } \\
\text { u.) }\end{array}$ & $\begin{array}{c}\text { System losses } \\
\text { with islanded MG } \\
(\mathrm{kW})\end{array}$ & R.F. \\
\hline $0-1$ & 2637.04 & 207.97 & 207.97 & 207.97 & 0.9620 & 66.43 & 0.079 \\
\hline $1-2$ & 2465.25 & 209.25 & 209.25 & 209.25 & 0.9644 & 57.99 & 0.085 \\
\hline $2-3$ & 2441.68 & 180.56 & 180.56 & 180.56 & 0.9649 & 56.47 & 0.074 \\
\hline $3-4$ & 2460.35 & 207.82 & 207.82 & 207.82 & 0.9647 & 57.34 & 0.084 \\
\hline $4-5$ & 2445.04 & 204.81 & 204.81 & 204.81 & 0.9648 & 57.00 & 0.084 \\
\hline $5-6$ & 2551.81 & 200.72 & 200.72 & 200.72 & 0.9632 & 61.95 & 0.079 \\
\hline $6-7$ & 3430.82 & 991.83 & 991.83 & 991.83 & 0.9501 & 114.27 & 0.289 \\
\hline $7-8$ & 3456.14 & 1097.50 & 1097.50 & 1097.50 & 0.9497 & 116.05 & 0.318 \\
\hline $8-9$ & 3322.75 & 1034.25 & 1034.25 & 1034.25 & 0.9518 & 106.48 & 0.311 \\
\hline $9-10$ & 3452.97 & 1144.07 & 1144.07 & 1144.07 & 0.9497 & 116.05 & 0.331 \\
\hline $10-11$ & 3349.45 & 1193.91 & 1193.91 & 1193.91 & 0.9513 & 108.69 & 0.356 \\
\hline $11-12$ & 4055.68 & 1058.90 & 1058.90 & 1058.90 & 0.9405 & 162.48 & 0.261 \\
\hline $12-13$ & 4313.70 & 1159.07 & 1159.07 & 1159.07 & 0.9366 & 184.49 & 0.269 \\
\hline $13-14$ & 4155.98 & 1110.08 & 1110.08 & 1110.08 & 0.9390 & 170.96 & 0.267 \\
\hline $14-15$ & 4092.92 & 1086.41 & 1086.41 & 1086.41 & 0.9399 & 165.83 & 0.265 \\
\hline $15-16$ & 4170.35 & 1179.56 & 1179.56 & 1179.56 & 0.9386 & 172.73 & 0.283 \\
\hline $16-17$ & 4173.88 & 1145.52 & 1145.52 & 1145.52 & 0.9386 & 172.83 & 0.274 \\
\hline $17-18$ & 3762.83 & 1029.46 & 1029.46 & 1029.46 & 0.9450 & 138.63 & 0.274 \\
\hline $18-19$ & 3721.74 & 1155.94 & 1155.94 & 1155.94 & 0.9457 & 135.22 & 0.311 \\
\hline 19-20 & 3864.76 & 1092.11 & 1092.11 & 1092.11 & 0.9434 & 147.04 & 0.283 \\
\hline $20-21$ & 3802.56 & 1170.05 & 1170.05 & 1170.05 & 0.9445 & 141.41 & 0.308 \\
\hline $21-22$ & 3585.00 & 1036.31 & 1036.31 & 1036.31 & 0.9477 & 125.20 & 0.289 \\
\hline $22-23$ & 2827.51 & 230.79 & 230.79 & 230.79 & 0.9591 & 76.74 & 0.082 \\
\hline $23-24$ & 2757.89 & 213.62 & 213.62 & 213.62 & 0.9602 & 72.80 & 0.077 \\
\hline
\end{tabular}




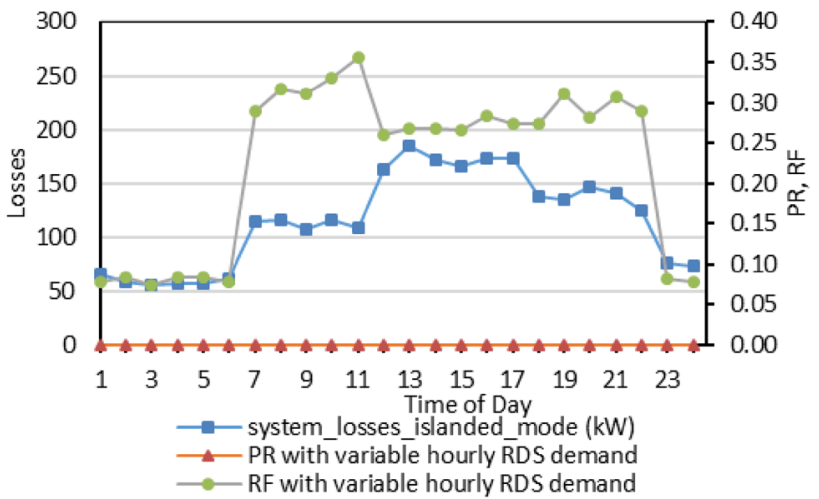

Figure 8. Correlation between system losses and relief factor (Islanded mode).

Table 4 shows that,

- Even when PR is zero, Relief Factor is nonzero.

Figure 8 illustrates the correlation between system losses and Relief Factor for islanded mode of the Microgrid.

Figure 8 shows that PR fails to analyze RDS performance due to islanded mode of Microgrid operation. However, Relief Factor being always nonzero, it is useful to analyze the performance of the RDS in the presence of the Microgrid. Presence of the Microgrid reduces the system losses as seen in figure 8.

The proper co-ordination of demand and supply in the Microgrid is used to assess RDS performance in terms of PR and Relief Factor. Relief Factor overcomes the drawback of PR for assessing the distribution system performance. Relief Factor analyses implications of the presence of a Microgrid on RDS performance especially in islanded mode of Microgrid operation. RDS performance is improved in both modes of Microgrid operation.

In this paper, an innovative factor is proposed to represent the reduction in stress of the RDS due to the presence of a Microgrid. The factor introduced in a new form is always nonzero irrespective of modes of Microgrid operation. Though it depends on the Microgrid generation, it is simple to implement.

\section{Conclusion}

The study has presented an evaluation of the performance of the radial distribution system in the presence of a Microgrid but independent of its modes of operation. Implications of the presence of a Microgrid on the radial distribution system are assessed by developing an algorithm in a two-step approach. Step one analysis includes the determination of performance criteria viz. voltage profile and real power loss of the RDS with and without Microgrid by power flow analysis using Backward Forward Sweep method. It is found that the presence of a Microgrid has enhanced the performance of the radial distribution system. In step two, the implications of the presence of a Microgrid on the RDS are assessed by correlating P.R., R.F. and system loss.

Power exported by a Microgrid is evaluated as Penetration Ratio. Penetration Ratio is the criterion to evaluate performance of the distribution system in the presence of a DG. This ratio is found to be zero in islanded mode and sometimes in grid connected mode of Microgrid. Penetration Ratio is zero when Microgrid acts as a load, self-sufficient mode or islanded mode. Relief to the RDS in the presence of a Microgrid in these three cases is different which can never be discriminated by the Penetration Ratio. Thus, a new index "Relief factor" is a better parameter for performance analysis of the distribution system as compared to Penetration Ratio.

Microgrid gives more relief to the RDS and improves its performance by better voltage profile and more loss reduction in both, islanded and grid connected mode. Gridconnected mode is useful for Demand Side Management (DSM) in the Maingrid.

Relief Factor brings the benefit to the Distribution System Operator (DSO) to consider both modes of Microgrid operation while analyzing distribution system performance.

\section{List of symbols}

$\mathrm{I}_{\mathrm{i}} \quad$ line current in $\mathrm{i}^{\text {th }}$ line

$\mathrm{Ri} \quad$ resistance of $\mathrm{i}^{\text {th }}$ line

$\mathrm{P}_{\mathrm{G}} \quad$ total active power supplied to RDS by the utility

$\mathrm{Q}_{\mathrm{G}} \quad$ total reactive power supplied to RDS by the utility

$\mathrm{P}_{\mathrm{D}} \quad$ total active power demand of RDS including Microgrid demand

$\mathrm{Q}_{\mathrm{D}} \quad$ total reactive power demand of RDS including Microgrid demand

$\mathrm{P}_{\text {loss }}$ active power loss in RDS

$\mathrm{Q}_{\text {loss }}$ total reactive power loss in RDS

$\mathrm{P}_{\mathrm{G} \mu \mathrm{G}} \quad$ active power generation of Microgrid

$\mathrm{Q}_{\mathrm{G} \mu \mathrm{G}}$ reactive power generation of Microgrid

$\mathrm{P}_{\mathrm{D} \mu \mathrm{G}}$ active power demand of Microgrid

$\mathrm{Q}_{\mathrm{D} \mu \mathrm{G}}$ reactive power demand of Microgrid

$\mathrm{P}_{\mu \mathrm{G}}^{\mathrm{in}} \quad$ active power exported by Microgrid to RDS

$\mathrm{N}$ number of generators in Microgrid

$\mathrm{m}$ number of lines in RDS

$\sigma \quad$ relief factor

$\lambda \quad$ penetration ratio

\section{References}

[1] Lasseter R H, Akhil A, Marnay C, Stephens J, Dagle J, Guttromson R, Meliopoulous A S, Yinger R and Eto J 2002 Integration of distributed energy resources: The CERTS Microgrid Concept. LBNL-50829: 1-26 
[2] Katiraei F and Iravani R 2008 Microgrids management. IEEE Power Energy Mag. 6(3): 54-64

[3] Costa P M and Matos M A 2009 Assessing the contribution of microgrids to the reliability of distribution networks. Electr. Power Syst. Res. 79(2): 382-389

[4] Balijepalli V S K M, Khaparde S A and Dobariya C V 2010 Deployment of microgrids in India. In: IEEE PES General Meeting, pp. 1-7

[5] Parhizi S, Lotfi H, Khodaei A and Bahramirad S 2015 State of the art in research on microgrid: A Review. IEEE Access 3: 890-925

[6] Mohammadi M, Hosseinian S H and Gharehpetian G B 2012 GA-based optimal sizing of microgrid and DG units under pool and hybrid electricity markets Int. J. Electr. Power Energy Syst. 35(1): 83-92

[7] Han Li, Eseye A T, Zhang J and Zheng D 2017 Optimal Energy management for industrial microgrids with high-penetration renewables. J. Prot. Control Mod. Power Syst. 1-14

[8] Zaheeruddin and MunishManas 2015 Renewable energy management through microgrid central controller design: An approach to integrate solar, wind and biomass with battery. Elsevier Energy Rep. 1: 156-163

[9] Katiraei F and Iravani R 2006 Power management strategies for a microgrid with multiple distributed generation units. IEEE Trans. Power Syts. 21(4): 1821-1831

[10] Yang N, Paire D, Gao F and Miraoui A 2013 Power management strategies for microgrid - A short review. In: IEEE Ind. Appl. Society Annual Meeting, pp. 1-9

[11] Mendis N, Mahmud M A, Roy T K, Haque M E and Muttaqi K M 2016 Power management and control strategies for efficient operation of a solar power dominated hybrid DC microgrid for remote power applications. In: IEEE Ind. Appl. Society Annual Meeting, pp. 1-8

[12] Kersting W H 1984 A method to teach the design and operation of a distribution system. IEEE Trans. Power App. Syst. PAS103(7): 1945-1952

[13] Ugranli F and Karatepe E 2013 Multiple-distributed generation planning under load uncertainty and different penetration levels. Int. J. Electr. Power Energy Syst. 6: 132-144

[14] Zehir M A, Batman A, Sonmez M A, Font A, Tsiamitros D, Stimoniaris D, Kollatou T, Bagriyanik M, Ozdemir A and
Dialynas E 2017 Impacts of microgrids with renewables on secondary distribution networks. Appl. Energy 201: 308-319

[15] Zhang J, Su S, Chen J and Hong F 2009 Stability analysis of the power system with the large penetration ratios of microgrids. In: Proceedings of International Conference on Sustainable Power Generation and Supply, Nanjing, China, pp. 1-5

[16] Buayai K and Kerdchuen T 2013 Influence of micro-grid in steady state performance of primary distribution system. Research J. Appl. Sci. Eng. Technol. 6(5): 819-824

[17] Torre D de la, Morillo J. L., Velasquez M. A. and Quijano N.,2014 "Technical assessment of microgrids integration into distribution systems," In: IEEE PES Transmission and Distribution Conference and Exposition - Latin America (PES T\&D-LA), Medellin, Colombia, pp. 1-6

[18] Karimi M, Mokhlis H, Naidu K, Uddin S and Bakar A H A 2016 Photovoltaic penetration issues and impacts in distribution network-A review. Renew. Sustain. Energy Rev. 53: 594-605

[19] Tonkoski R, Turcotte D and EL-Fouly T H M 2012 Impact of high PV penetration on voltage profiles in residential neighborhoods. IEEE Trans. Sustain. Energy 3(3): 518-527

[20] Boljevic S 2015 Maximizing Penetration of Distributed Generation in Existing Urban Distribution Network (UDN). Ph.D. Thesis, Dublin Institute of Technology, Ireland

[21] Chis M, Salama M M A and Jayaram S 1997 Capacitor placement in distribution systems using heuristic search strategies. In: Proc. IEE-Gen. Trans. Distrib. 144(3): 225-230

[22] Chaphekar S N, Panandikar H S and Dharme A A 2016 Availability based distributed resource management of microgrid. In: IEEE Seventh Power India International Conference (PIICON), Bikaner, India, pp. 1-6

[23] Details of solar irradiance and ambient temperature. http:// www.nrel.gov/international/ra_india_html Accessed July 25 2017

[24] Details of wind turbine. http://www.ewtdirectwind.com. Accessed July 202017

[25] Details of TOD tariff. http://www.gercin.org/terifforder. Accessed August 102017 